distinguished oceanographer Roger Revelle from a paper they had jointly published expressing the view that the scientific basis for global warming was insufficient to justify immediate policy action at that time. A libel lawsuit filed by Singer against an individual working closely with Senator Gore was settled in 1994 by a full and complete admission by the individual of facts at issue, with a retraction and apology for the insinuations that led to the action being brought.

A common theme throughout the tales told in Politicizing Science is the notion of the precautionary principle or, more prosaically, "Look before you leap". We should always be conscious of the possible consequences of our scientific endeavours and cautious in the deployment of new applications of science. But, taken to its extreme, the precautionary principle can result, as Nilsson says of the situation in present-day Sweden, in "Look, but never leap".

The antidote to an overdose of the precautionary principle is the discipline of risk analysis and management, as argued many times by the contributors to this book. Risk analysis attempts to measure the risk of a given technology to the individual against its potential benefit to society as a whole. In the words of Chauncey Starr, one of the founders of probabilistic risk analysis, "the moral high ground assumed by well-meaning activists for single health causes may well be socially immoral when evaluated by the welfare of the total population".

Unfortunately, Politicizing Science lacks any discourse on how best to 'de-politicize' science. Here and there are hints that we need to 'get more involved'. Many, if not most, scientists are put off by the political process, forgetting that the pursuit of success in one's own profession is often quite political. We should seek and cultivate those rare individuals who combine the ability to carry out creative science with a personal populist appeal and an unshakeable belief in that paradigm of democracy: "You can't fool all of the people all of the time."

Perhaps the greatest native-born American scientist of my generation was Richard Feynman. His untimely death took from us not only a giant in physics but also a man of the people who was just beginning to capture the popular imagination and trust - and liked it. Think of a Feynman in the US Senate or White House, and the impatience he would have had with the cold-fusion imbroglio and the hand-wringing over the precautionary principle. Somewhere, sometime, another like Feynman is sure to surface. When that happens, let's campaign to get him or her elected to executive or legislative power in Washington, London, Moscow or Beijing, or wherever they're most needed. Paul M. Grant is a science fellow at the Electric

Power Research Institute, 3412 Hillview Avenue, Palo Alto, California 94303, USA.

\section{Smashed into orbit}

The Big Splat, or How Our Moon

\section{Came to Be}

by Dana Mackenzie

John Wiley: 2003. 240 pp.

$\$ 24.95$ (US), \$38.95 (Canada), $£ 17.50$

\section{Joseph A. Burns}

Ours is a violent world and always has been. The whole Universe was produced in an unimaginable cataclysm, the Big Bang, about 13.7 billion years ago. Much later, 4.6 billion years ago, a nearby supernova explosion may have triggered the collapse of the protosolar cloud that became our Solar System.

This slim volume, written straightforwardly and engagingly by Dana Mackenzie, a mathematician turned freelance writer, describes how a collision produced Earth and the Moon. The giant-impact hypothesis — the 'Big Splat' of the title — maintains that an object larger than Mars slammed into proto-Earth during the final stages of its accumulation, giving birth to the Moon.

The Big Splat lays out ancient thoughts about the Moon's place in the cosmos, sketches the contributions of the greats of classical physics (Galileo, Kepler, Newton and Laplace), detours into topics such as celestial mechanics and navigation, recalls the Apollo programme, and finally describes the collisional model of the Moon's origin.

This historical tour turns out to be somewhat circular. The first known attempt to explain the Moon's origin occurred in the fifth century BC, when the Greek thinker Anaxagoras, after viewing a meteorite that had been observed falling from the sky, speculated that all celestial objects were glowing 'stone stars' flung off Earth. Apparently he got it right in the case of the Moon, but astronomy textbooks only a generation ago were not so sure. They still listed three scenarios for lunar origin that had been developed in some mathematical detail a century earlier: the reclusive mathematician Edouard Roche contended that the two bodies were siblings, having 'co-accreted' as an orbiting binary; the scholarly George Darwin (son of Charles) promoted the idea that the Moon was our planet's child, having split off when a rotationally distorted primordial Earth became unstable; and later a cantankerous crackpot, T. J. J.See, argued that the Moon formed elsewhere, only to be snared intact by our planet.

These classical hypotheses were still debated vigorously as the space age dawned, even though the flaws of each were well recognized. Co-accretion would yield less angular momentum - the combined 'spin' of the Earth and Moon about one another than the Earth-Moon system in fact has. Fission would require much more angular momentum than exists now, and there is no plausible explanation for how it could have started off. And the capture of an intact body is ridiculously improbable.

The Nobel Prize-winning chemist Harold Urey believed that the Moon, alone among the terrestrial bodies, was formed cold. To test this hypothesis of the Solar System's formation, Urey used his political influence in 1958 to get NASA's founding mission statement to focus on the origin of the Universe, which was "written plain to our eyes on the surface of the Moon". So Earth's only satellite became the primary scientific target of the US space programme. The lunar rocks returned by the Apollo and Luna missions showed that the Moon had much lower proportions of iron and volatiles than Earth, but their isotopic signatures had striking similarities to Earth's - as well as occasional differences. As is often the case, no model of origin survived its confrontation with data.

The final third of this book describes the

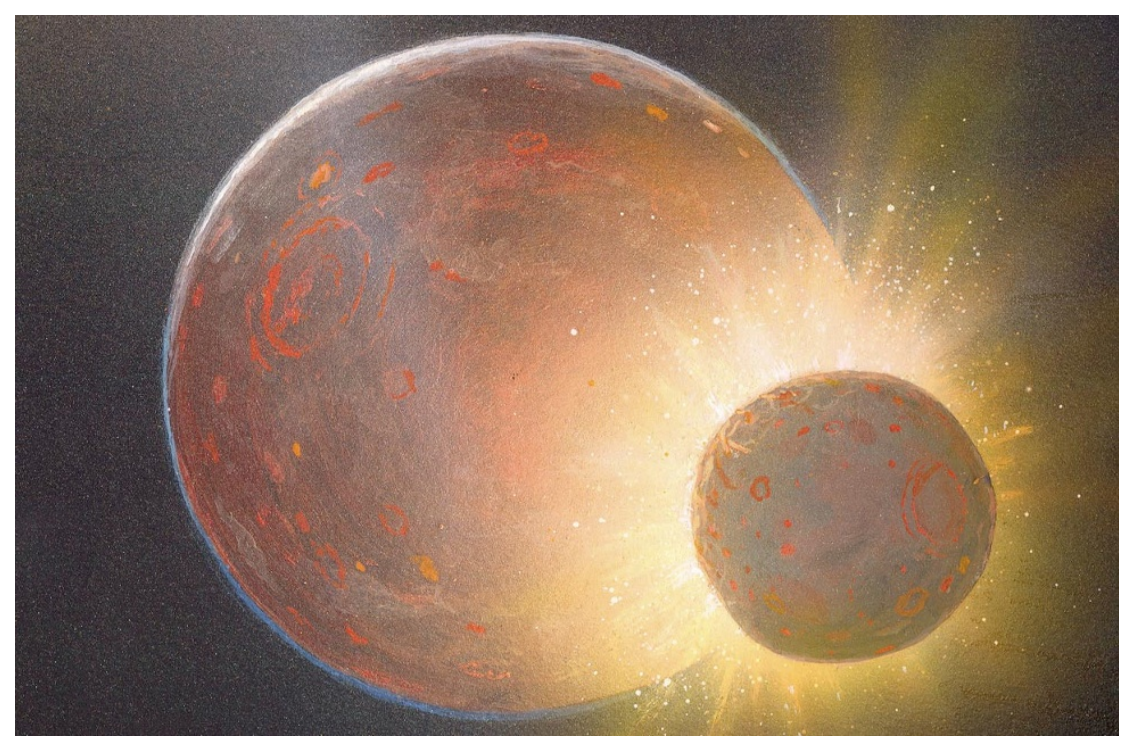

Splat! A giant object crashing into the proto-Earth may have given rise to the Moon. 
An Investigation of the Principles of Knowledge and of the Progress of Reason, from Sense to Science and Philosophy

by James Hutton

1794

Facsimile edition: Thoemmes: 1999.

\section{Chosen by Paul N. Pearson}

Following the publication of On the Origin of Species in 1859, Charles Darwin learned (and duly acknowledged) that two previous authors had anticipated the theory of evolution by natural selection. The first account to come to light was by Patrick Matthew, who had briefly outlined the mechanism in an appendix to his 1831 book On Naval Timber and Arboriculture. The second was by the physician William Wells, who had speculated on selection and human evolution in 1818.

But some 50 years ago, E. B. Bailey described a still older version of the selection theory from a 1797 manuscript by the geologist James Hutton now chiefly famous for his early appreciation of geological time. Unfortunately, this work, entitled the Elements of Agriculture, never appeared in print. Now a more complete, published account has come to light from 1794.

An Investigation of the Principles of Knowledge is an intimidating philosophical treatise of three volumes, running to 2,138 pages in its original edition. Hutton's friend and biographer, John Playfair, presciently noted: "The great size of the book, and the obscurity which may justly be objected to many parts of it, have probably prevented it from being received as it deserves." The selection theory is the subject of an entire chapter in the second volume (see supplementary information). Hutton mused:

"If an organised body is not in the situation and

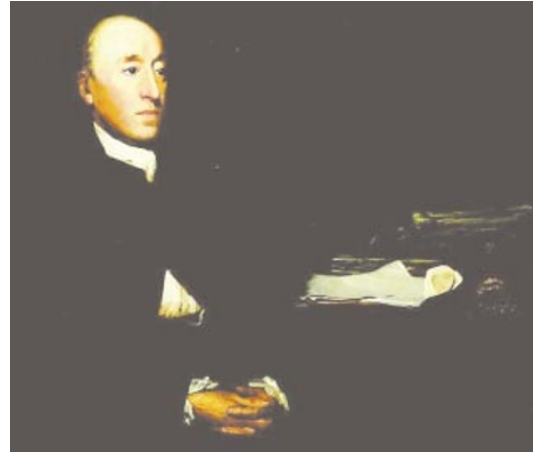

The original Origin? James Hutton described natural selection as long ago as 1794 .

circumstances best adapted to its sustenance and propagation, then, in conceiving an indefinite variety among the individuals of that species, we must be assured, that, on the one hand, those which depart most from the best adapted constitution, will be most liable to perish, while, on the other hand, those organised bodies, which most approach to the best constitution for the present circumstances, will be best adapted to continue, in preserving themselves and multiplying the individuals of their race."

For example, Hutton describes that in dogs that relied on "nothing but swiftness of foot and quickness of sight" for survival, "the most defective in respect of those necessary qualities, would be the most subject to perish, and that those who employed them in greatest perfection would be best preserved, consequently, would be those who would remain, to preserve themselves, and to continue the race". But if an acute sense of smell was "more necessary to the sustenance of the animal", then "the natural tendency of the race, acting upon the same principle of seminal variation, would be to change the qualities of the animal, and to produce a race of well scented hounds, instead of those who catch their prey by swiftness". The same "principle of variation" must also influence "every species of plant, whether growing in a forest or a meadow".

Hutton was no mere armchair theorist. $\mathrm{He}$ came to his principle after experiments in plant and animal breeding, some of which are described in the Elements of Agriculture manuscript. These experiments led him to distinguish between seminal variation, which occurs in sexual reproduction and is heritable, and non-heritable variation, caused by the circumstances of soil and climate.

It is important to stress, however, that while he used the selection mechanism to explain the origin of varieties in nature, he specifically rejected the idea of evolution between species as a "romantic fantasy". Indeed, he was a deist and regarded the capacity of species to adapt to local conditions as an example of benevolent design in nature.

It may be more than coincidence that Wells, Matthew and Darwin were all educated in Hutton's home town of Edinburgh, a place famous for its scientific clubs and societies. Studies of Darwin's private notebooks have shown that he came to the selection principle independently of earlier authors, as he always maintained. But it seems possible that a half-forgotten concept from his student days resurfaced afresh in his mind as he struggled to explain the observations of species and varieties compiled on the voyage of the Beagle. Paul N. Pearson is at the School of Earth, Ocean and Planetary Sciences, Cardiff University, Cardiff CF10 3YE, UK.

Supplementary information The full text of Hutton's chapter from The Principles of Knowledge and other relevant extracts from Elements of Agriculture are available on Nature's website. development of the now-preferred scenario for how the Moon came to be. By the mid1970s the analytical ideas of the Soviet cosmogonist V.S. Safronov about the role of impacts in forming the planets of our Solar System had travelled west, where they were tested and extended numerically by George Wetherill and by the Planetary Science Institute. Bill Hartmann and Don Davis, from the latter group, realized that the final objects to accumulate into the terrestrial planets must have been massive and would have careened through the inner Solar System. They concluded that the Moon could have been born from the final collision of such an object, and argued that the material thrown off protoEarth would have been from its iron-poor surface layers and that volatiles would have boiled off, explaining the Moon's gross composition.

Independently, Al Cameron and Bill Ward noted that the angular momentum of the entire Earth-Moon system required an impact from at least a Mars-sized projectile, and began to analyse the likely evolution of the flattened, Earth-circling cloud of vaporized material that any giant collision would have generated. The Moon, accumulated from this orbiting debris through much the same processes as the planets themselves, would contain material from both Earth's mantle and the projectile. Despite their plausibility and close match with known facts, these works attracted little attention and languished along with all lunar studies during the early 1980s.

Languished, that is, until a conference in 1984, held in Kona, Hawaii, brought together dynamicists, cosmochemists and geophysicists to consider the Moon's origin. By this time, impacts were accepted as shapers of life, following the proposal of Luis and Walter Alvarez that linked an asteroid collision with the dinosaurs' demise and other mass extinctions at the end of the Cretaceous period. As the conference proceeded, it became clear that a consensus had silently emerged in the various disciplines: each, unaware of the other, favoured a collisional beginning for the Moon.

In the past two decades, there have been increasingly sophisticated simulations of a massive impact and the evolution of the resulting debris disk, and lunar samples and meteorites have been scrutinized. The giantimpact hypothesis does well in explaining the observed physical, thermal and geochemical properties of the Earth-Moon system. Plausible modifications to the original theory may overcome the remaining faults: contemporary models suggest that Earth was not fully grown when it was struck by an even larger projectile than was previously thought.

Besides telling an interesting tale well and elucidating how science progresses, Mackenzie's book emphasizes the fact that impacts have been the primary creative and destructive process throughout the history of the Solar System. Some today wonder whether the final violence that ends civilization will be another such collision - rather than a catastrophe of our own making.

Joseph A. Burns is in the Departments of Theoretical and Applied Mechanics and of Astronomy, Cornell University, Ithaca, New York 14853, USA. 